Chapter 9

\title{
Low and Medium Calorific Value Gasification Gas Combustion in IC Engines
}

\author{
Ftwi Yohaness Hagos, Abd Rashid Abd Aziz, \\ Shaharin A. Sulaiman and \\ Bahaaddein K. M. Mahgoub
}

Additional information is available at the end of the chapter

http://dx.doi.org/10.5772/64459

\begin{abstract}
Higher hydrogen to carbon ratio of gasification gases produced from solid fuels has been utilized in internal combustion engines (ICE) since long ago. Advancements in the conversion technologies and the abundant availability of solid fuels added with advancements in the technology of gas engines and their fuelling system have renewed the interest and are believed to be transition fuels from carbon based to hydrogen based. Over the past 30 years, there were many trials to bring back the gasification gas technology in ICE. This study is mainly focused on the investigation of technical challenges with lower and medium calorific value gasification gases in IC engines The range of operation of these fuels is found to be influenced by available injection duration and injector pulse width in direct-injection spark-ignition engines. The lower calorific value of these gases also make them less competitive to $\mathrm{CNG}$ and $\mathrm{H}_{2}$ in the dual fueling in $\mathrm{CI}$ engine even though they have better advantage in the emissions. Furthermore, red glow color deposit was spotted on the surface of the combustion chamber after short running on all fuels that was resulted from decomposition of iron pentacarbonyl $\left(\mathrm{Fe}(\mathrm{CO})_{5}\right)$ contaminants.
\end{abstract}

Keywords: gasification gas, fuel, combustion, IC engine, SI, CI, technical challenges

\section{Introduction}

The focus of utilization of gasification gases was limited in the stationary power plants since the post-World War II (WW II). The current energy statuesque is getting challenged due to the 
abundant availability of solid fuels and advancement in the solid-togas conversion technologies. This chapter intends to give the results of the study of utilization of gasification gases in internal combustion engines (ICEs) to appraise the current knowledge on the combustion, performance and emissions of both lower and medium calorific value gasification gases. Both spark ignition (SI) and compression ignition (CI) engines are considered in the study. The current energy scenario, historical background, the solid fuel potential, advancement in the conversion technologies, basic fuel properties comparison of representative gasification gases with that of CNG and hydrogen and the compositions of gasification gases from medium- and large-scale gasification plants are covered in the introduction part. The combustion, performance and emissions of gasification gases in both SI and CI are addressed in Sections 2 and 3. The safety issue of gasification gases and their overall technical challenges are discussed in Sections 4 and 5. Finally, a concluding remark and future directions in the study of these fuels is presented in Section 6 .

\subsection{Energy scenario}

During the invention of ICEs, the energy sources were gaseous fuels and powders. In the mid of the 19th century, a French Engineer J. J. Étienne Lenoir developed a double acting SI engine, and later in 1876 [1], first gasoline-fuelled ICE was built. The first commercial vehicle in Germany was produced by Carl Benz 1886 [2], and by 1890, more than 50,000 of such commercial vehicles were sold in Europe and USA [1]. Later, the expansion of automotive production by Henry Ford in 1910 has further initiated the era of fossil fuels as an energy sources [2]. The demand for gasoline increased by fivefold in the years from 1907 to 1915 and as a result William Burton innovated the idea of thermal cracking of crude oil in 1913 [1]. Advancements in the fossil fuel extraction methods on the one hand and cheaper cost of production of cars on the other hand have had significant contribution in the growth of ICE use in transport automobiles. Thus, the fuel consumption grew sharply from 11 billion litres in 1919 to 57 billion litres in 1929 and then to 176 billion litres in 1955 [2]. World War II led to the shortage of gasoline and as a result there was a brief stagnation in the utilization of fossil fuel mainly for private use. During this period, development of wood gas vehicles expanded all over the world. More than a million of such vehicles had been produced and were functioning globally by the end of the war [3]. However, petrol domination at the end of 1940s has led to the quick exit of these types of engines out of market.

The expansion of the ICE-driven automobile transport has dramatically transformed the global economic and technological landscape. As a result, human life got more attachment with ICE and with their fuel and its consumption grew unrestrained. The negative effect of fossil fuels on the environment was not noticed for up to half century. Environmental pollution, mainly from the transportation sector, first came into attention at the end of 1940s and beginning of 1950s. During this period, it was noticed that the major contributor for the pollutant emissions of hydrocarbons (HCs), nitrogen oxide $\left(\mathrm{NO}_{x}\right)$ and carbon monoxide $(\mathrm{CO})$ was the transport sector mainly automobiles. In 1960s, the state of California and later the whole nation (USA) adapted emission standard for automobile [1]. Added to this, there came a geopolitical situation in the Middle East in 1970s that resulted global energy crisis. Concern regarding the 
long-term availability of fossil fuels started to be raised along with it. As a result, most nations started to revisit their energy policies towards fossil based fuels to address the two scenarios. Similarly, alternative source of energy became a centre of research in the scientific world.

Different fuels have been investigated as alternative fuels for ICE over the years. Natural gas, hydrogen, alcohols (ethanol and methanol) and biodiesel are the most common alternative fuels which have received greater attention over the period. Even with such extended efforts, still the transport sector is mainly dependent on the much polluting and unsustainable fossil based fuels. Energy demand in the transport sector is expected to double from the current 60 trillion passengers per tonne-km in 2050, most growth coming from passenger light-duty vehicles in developing countries [4]. This is mainly due to an increase in population and ownership of motorized vehicles in both developing and developed countries and an increased air travel as a result of urbanization in developing world. The global population is projected to reach 9.6 billion from the current 7.2 billion mark in 2050 [5]. Furthermore, developing countries will become economically stronger. As a result, the global vehicle ownership is expected to triple by 2050; up to $80 \%$ of the growth comes from the rapidly growing counties [6]. Due these concerns, solid fuels are receiving greater attention as a source of energy due to the huge burden on the conventional and other renewable fuels. Solid-to-gas fuel conversion technologies have advanced dramatically over years of research and development. The current article is focused on the investigation of the gaseous fuels processed from solid fuels employed in ICE. Even though the lower and medium calorific gasification gases are receiving more attention towards their application in ICE, more focus is still given in the area of combustion, performance and emissions in a gasifier-integrated engine where such arrangement is not practical with the current mobility demand. Therefore, the major research questions in the current article are: (i) does separation of gasifier and the engine arrangement affect the combustion, performance and emissions as compared to the gasifier-integrated engine? What are the major technical challenges designers and automotive developers should be concerned of? To address, these research gaps, lower and medium calorific value gasification gases in ICE and their technical challenges are investigated.

\subsection{Solid fuel potential}

Solid fuel is the oldest source of energy for mankind which has been utilized since the early Stone Age era. Our ancestors first started to use fire 250,000 year ago with solid fuels such as wood, charcoal, peat, straw and dried dung [7]. Humans first used fire for cooking and heating purposes. Due to their abundant availability and easy for collection, biomass remained as a dominant solid fuel until the beginning of the industrial revolution. It was during the industrial revolution the utilization of solid fuels expanded to other areas such as smelting of metallic ores (iron, copper, silver, etc.) and steam engine [8]. The diversification of application of solid fuels prompted the search for other types of fuels. As a result, coal has become a dominant source of energy in this era. The invention of steam engine has further facilitated the mining of coal from underground sources by pumping water from coal mining area. The higher energy density of coal gave it higher preference compared to wood and other solid biomass $[8,9]$. 
Coal is the most abundant energy resource with an estimated reserve of 18,000 Gtoe [10]. However, the recoverable coal reserve is much lower [11]. The UK Solid Fuel Association estimated the reserves as a reserve for 118 years at its current rate of production. Even though percentage share of solid fuels in the total energy mix started to shrink since the beginning of the twentieth century, solid fuels are still the major contributors of the economy. They are the dominant energy sources for electricity and in the industrial processes (steel, cement, sugar, pulp and paper) [12]. According to the 2013 International Energy Outlook published by the US Department of Energy, electricity generation is to grow annually by $3.1 \%$ in the non-OECD countries (countries outside the Organization for Economic Cooperation and Development) while $1.1 \%$ annually in the OECD nations [13]. As a result, the global solid fuel consumption is rising annually. Coal alone is expected to rise at an annual average rate of $1.3 \%$ to 220 quadrillion Btu in 2040 [13]. The diverse application and utilization of these fuels make them preferred fuels. Besides, their abundance, their ability to convert to other form of energy and uncertainty with the gaseous and liquid fossil fuels make solid fuels the future energy supply [12]. Even though solid fuels have had such recognition in the energy sector, their direct applications as a source of heat become almost impossible these days. Beside their inconvenience in handling, there are stringent regulations at the present time due to the environmental issue. Different measures have been implemented for the improvement of pollutant emissions in the direct conversion solid fuels. However, the conversion of solid fuels to gaseous and liquid form is preferred especially in the transportation sector.

\subsection{Advancements in the fuel conversion technologies}

Gasification is a thermo-chemical conversion process that converts solid fuels into gaseous by increasing the hydrogen-to-carbon ratio through the breakdown of the feedstock. The process involves drying, pyrolysis combustion and reduction sub-processes. The carbon conversion efficiency of the latest gasifiers is estimated to be around $75 \%$. The name gasification gas is a general term for any gasification product also known as syngas, town gas and producer gas [14]. Gasifying agent is the most significant parameter that affects the yield from the thermochemical conversion process [15]. The main gasifying agents used in the process are oxygen, steam, and air. Gasification gas produced using steam and oxygen as a gasifying agent is called medium calorific value gasification gas (simply syngas) and its heating value ranges from 10 to $28 \mathrm{MJ} / \mathrm{Nm}^{3}$ [15]. On the other hand, gasification gas produced using air as a gasifying agent is called lower calorific value gasification gas or producer gas and its heating value ranges from 4 to $7 \mathrm{MJ} / \mathrm{Nm}^{3}[16]$.

The current practice in the biomass use as an energy source through gasification is by coupling the gasifier to the prime mover. In this arrangement, the gasifier is sized based on the capacity of the prime mover (turbine). As a result, the gasifier operates only during the time of peak demand for electricity. Even though there is surplus of raw material (solid fuels), the gasifier cannot be operated as there is no storage system arrangement. That is why people are trying to upgrade syngas into dimethyl ether (DME) and other oxygenated hydrocarbon fuels [17, 18]. In recent years, there are some efforts to integrate a storage system in the gasification process [19-21]. If the gasifier system is separated from a prime mover, the gasifier can be sized 
to produce extra gasification gas that can be stored for the utilization at the time of peak demand and further sourced to the market in the transport sector and chemical industry.

\subsection{The history of gasification gas in the automotive sector}

There are reports of the employment of various ranges of gasification gases in the IC engine over the years since the inception of the Imbert gasifier around 1920. During the World War II, there was severe shortage of gasoline globally and all private-owned cars and tracks were redesigned to operate with gasification gases by erecting an Imbert gasifier. As it is also stated in Section 1.1, the number of cars running on producer gas at the time of WW II was estimated to 7 million by Sridhar et al. [22]. After the war, petroleum distribution returned back to normal and it led to the quick exit of these engines out of market. Besides the petroleum abundance, there were operational and technical problems that prompted for the fast exist. These problems are summarized by Hagos et al. [23]. Since then, the application of gasification gases shifted into the integrated gasification combined cycle as a stationary power generation system. However, even in this period, countries did not totally give up on the use of such fuel in the mobile engine applications. The United States of America is promoting the application of this technology as a backup energy supply source in the event the country faces petroleum crisis [24].

Since the global energy crisis of the 1970s, the research on both the lower and medium calorific value gasification gases was again intensified because in one part the gasification technologies started to advance and on the other hand the price of petroleum increased. There are many results published with different success rates on the employment of these fuels on the carburetted and port-injected SI Engines [22, 25-47] and dual fuelling on the CI engines [4854]. Gasification gases (both producer gas and syngas) in a direct-injection (DI) SI engines has never been studied except the works by the authors of this article [23, 55-60]. Their combustion behaviour and performance and emission characteristics are studied for the broader range of gasification gas species and are reported elsewhere. This chapter concentrates on the summary of the combustion, performance and emission characteristics of representative of gasification gases over a wider range of operation conditions in both the DI SI engine and dual fuelling CI engine. Besides, the technical challenges observed during the study of these gases in ICEs will be emphasized in the current work. Unlike to the conventional fuels, there is no suitable predictive tool (Kiva, Forte, and GT Power) for the effect of property of such fuels on the optimization of combustion, performance and emissions. The current work will provide additional information for the development of alternative fuels.

\subsection{Properties of gasification gas and their scope in IC engines}

Engine output is mainly dependent on the chemical energy released as a result of combustion of the fuel inducted. Combustion in ICE is influenced by the nature of the fuel, the oxidizer and the geometry of the chamber among others. Depending up on the mode of gasification, gasifying agent and the solid fuel used, the constituent gases $\left(\mathrm{H}_{2}, \mathrm{CO}, \mathrm{CH}_{4}, \mathrm{~N}_{2}\right.$ and $\left.\mathrm{CH}_{4}\right)$ of gasification gas are varied. Not all gasification gases serve as fuels for ICEs. Analysis of different properties of fuels such as energy content, flammability limit, laminar flame speed 


\begin{tabular}{|c|c|c|c|c|c|c|}
\hline \multirow{2}{*}{\multicolumn{3}{|c|}{ Properties }} & \multicolumn{2}{|c|}{ Gasification Gases } & \multirow{3}{*}{$\begin{array}{c}\text { CNG } \\
75.0\end{array}$} & \multirow{3}{*}{$\begin{array}{c}\mathrm{H}_{2} \\
\\
0.0\end{array}$} \\
\hline & & & \multirow{2}{*}{$\begin{array}{c}\mathbf{5 0} \% \mathrm{H}_{2-} \\
\mathbf{5 0} \% \\
\mathrm{CO}[\mathbf{5 5}] \\
40.0\end{array}$} & \multirow{2}{*}{$\begin{array}{c}\begin{array}{c}19.2 \% \mathrm{H}_{2}, 29.6 \% \mathrm{CO} \\
5.3 \% \mathrm{CH}_{4}, 5.4 \% \mathrm{CO}_{2} \\
\text { and } 40.5 \% \mathrm{~N}_{2}[57]\end{array} \\
21.15\end{array}$} & & \\
\hline \multirow{4}{*}{$\begin{array}{l}\text { Compos } \\
\text { ition, } \\
\text { weight } \\
\%\end{array}$} & \multicolumn{2}{|c|}{ Carbon } & & & & \\
\hline & \multicolumn{2}{|c|}{ Hydrogen } & 6.67 & 2.56 & 25.0 & 100 \\
\hline & \multicolumn{2}{|c|}{ Oxygen } & 53.33 & 28.27 & 0.0 & 0.0 \\
\hline & \multicolumn{2}{|c|}{ Nitrogen } & 0.0 & 48.5 & 0.0 & 0.0 \\
\hline \multicolumn{3}{|c|}{ Molecular weight $(\mathrm{g} / \mathrm{mol})$} & 15.0 & 23.2 & 16.04 & 2.02 \\
\hline \multicolumn{3}{|c|}{ Density at $0^{\circ} \mathrm{C}$ and $1 \mathrm{~atm}\left(\mathrm{~kg} / \mathrm{m}^{3}\right)$} & 0.67 & 1.04 & 0.75 & 0.09 \\
\hline \multicolumn{3}{|c|}{ Specific gravity at $0^{\circ} \mathrm{C}$ and $1 \mathrm{~atm}$} & 0.52 & 0.8 & 0.58 & 0.07 \\
\hline \multirow{2}{*}{\multicolumn{2}{|c|}{$\begin{array}{l}\text { Stoichiometric } \\
\text { air-fuel ratio }\end{array}$}} & Molar Basis & 2.38 & 1.66 & 9.7 & 2.38 \\
\hline & & Mass Basis & 4.58 & 2.07 & 17.2 & 34.3 \\
\hline \multicolumn{3}{|c|}{$\begin{array}{l}\text { Stoichiometric volume } \\
\text { occupation in cylinder, \% }\end{array}$} & 29.6 & 37.6 & 9.35 & 29.6 \\
\hline \multirow{2}{*}{\multicolumn{2}{|c|}{$\begin{array}{l}\text { Lower calorific } \\
\text { value }\end{array}$}} & $\mathrm{MJ} / \mathrm{Nm}^{3}$ & 11.65 & 7.67 & 38.0 & 10.7 \\
\hline & & $\mathrm{MJ} / \mathrm{kg}$ & 17.54 & 7.47 & 47.1 & 120.2 \\
\hline \multirow{2}{*}{\multicolumn{2}{|c|}{$\begin{array}{l}\text { Stoichiometric } \\
\text { Mixture } \\
\text { Energy density } \\
\left(\mathrm{MJ} / \mathrm{Nm}^{3}\right)\end{array}$}} & $\begin{array}{l}\text { Mixture } \\
\text { aspirated }\end{array}$ & 3.3 & 2.73 & 2.9 & 3.2 \\
\hline & & Air Aspirated & 4.45 & 4.19 & 3.60 & 4.54 \\
\hline \multirow{2}{*}{\multicolumn{2}{|c|}{$\begin{array}{l}\text { Flammability } \\
\text { Limit, \% vol. of } \\
\text { fuel in air }\end{array}$}} & Lower & 6.06 & 13.4 & 5.3 & 4.0 \\
\hline & & Higher & 74.2 & 57.9 & 15.0 & 74.2 \\
\hline \multicolumn{3}{|c|}{ Laminar Flame Velocity $(\mathrm{cm} / \mathrm{s})$} & 180 & 50 & 30 & 210 \\
\hline \multicolumn{3}{|c|}{ Adiabatic Flame Temperature, $\mathrm{K}$} & 2385 & 2200 & 2220 & 2383 \\
\hline \multicolumn{3}{|c|}{ Auto-ignition Temperature, $\mathrm{K}$} & $873-923$ & 898 & 813 & 858 \\
\hline
\end{tabular}

Table 1. Summary of the properties of different gasification gases and their comparison to $\mathrm{CNG}$ and $\mathrm{H}_{2}$.

and flame temperature helps to classify those gasification gases that can be used in ICEs. The comparison of CNG with the conventional fuel in IC engines is widely available in the literature. On the other hand, fuel characteristic requirements of liquid and gaseous fuels are different. Therefore, CNG representing the hydrocarbon-based fuels and $\mathrm{H}_{2}$ that represent the renewable and zero emission fuels are taken for comparison in the current work. Generally, gasification gases are broadly classified into lower and medium calorific values depending on the type of gasifying agent and thereby with the nitrogen content. For air as a gasifying agent, roughly up to $50 \%$ of the constituent gases is nitrogen. If oxygen or steam is used as a gasifying agent, the constituent gases of the gasification gas are without nitrogen. Table 1 shows the detailed comparison of properties of two gasification gases that represent typical medium and lower calorific value fuels from biomass gasification, $\mathrm{CNG}$ and hydrogen. The summary of the fuel characteristics of these fuels could help in the understanding of combustion, performance and emissions behaviour in ICE [55]. All gasification gases are oxygenated fuels with the 
medium calorific value gasification gas having the highest oxygen content at $53.33 \mathrm{wt} \%$. The density of gasification gases are in the range of the density of the CNG with higher density observed in the lower calorific value gasification gases. The main concern with the gasification gases is the weight-based stoichiometric air-fuel ratio with 2.07 and 4.58 for lower and medium calorific value gasification gases, respectively, as compared to 17.2 for $\mathrm{CNG}$ and 34.3 for $\mathrm{H}_{2}$. On the other hand, gasification gases have better mixture energy density at stoichiometric condition for the air aspirating engine (DI) as compared to CNG and even at par with $\mathrm{H}_{2}$. All gasification gases have the upper hand in both the flammability limit and laminar flame velocity as compared to CNG. Similarly, they have higher auto-ignition temperature as compared to both $\mathrm{CNG}$ and $\mathrm{H}_{2}$.

\subsection{Typical gas compositions from practical large-scale gasification processes}

Improvements in technology have increased the confidence among investors on large-scale commercial biomass gasification plants. In this chapter, large-scale gasification plants shall be referred to those with thermal capacity of above $10 \mathrm{MW}_{\mathrm{th}}$ [61]. Since the 1980s, the number of successful large-scale biomass gasification plants has increased. Currently, the largest planned biomass gasification plant is located in Vaasa, Finland. The plant, which is owned by Metso [62], uses wood-based biomass, is expected to deliver 140 MWe of electricity. Most of the gasification plants are intended for electrical power generation, resulting electricity that is usually injected into the main grid. In one of the latest biomass gasification plants in Gothenburg, Sweden, which uses forest residues as feedstock, the resulting syngas is fed into the natural gas grid [63]. Known as the GoBiGas project, the plant utilizes a $32 \mathrm{MW}$ dual fluidized bed gasifier to produce about $20 \mathrm{MW}$ of substitute natural gas.

The composition of syngas mainly depends on the feedstock, due to diversity in the key characteristics of different feedstocks vis-à-vis physical and chemical properties, lignocellulosic composition, energy content, morphological characteristics, ash content, bulk density, and a few other properties [64]. Apart from feedstock, the type of gasifier [65] and the operating conditions also play important roles in determining the composition of syngas [66] because the complex heterogeneous solid-gas and homogenous gas-gas chemical reactions taking place during gasification are highly dependent on the operating conditions such as equivalence ratio of gasification, reactor temperature, moisture content [67] and the gasifying medium used. The heating value of the syngas depends on its composition.

Table 2 shows a range of selected large-scale biomass gasification plants, their capacities and gas compositions. Clearly, most of the plants are located in Europe, where strong interest on clean energy is present, and supports from the government and investors are high. Because of its superiority in technology and market, circulating fluidized bed (CFB) is shown in the table as the most preferred type of gasifier used for large-scale gasification plants. On feedstock, Table 2 shows that wood-based materials are preferred due to their availability in developed countries. The authors recognize the existence of other similar large-scale biomass gasification plants. However, detailed information about their operating conditions and their gas compositions is presently not available. The gas compositions, in volume percentage, listed in Table 2 are $\mathrm{CO}_{2}, \mathrm{~N}_{2}, \mathrm{CO}, \mathrm{H}_{2}$ and $\mathrm{CH}_{4}$. There are also other kinds of gases reported for the plants such 
as ethane, but their amounts are negligible. Of all the gases listed in Table 2, only CO, $\mathrm{H}_{2}$ and $\mathrm{CH}_{4}$ can be used as fuel. Overall, $\mathrm{CO}$ constitutes the largest fuel gas component in most of the plants listed, with the exception of the Viking DTU [68] plant in Denmark, which was aimed to produce more $\mathrm{H}_{2}$. The highest generation of $\mathrm{CO}$ occurs at the Vermont SilvaGas plant [69] in the USA at $44 \%$ although the composition of $\mathrm{N}_{2}$ was never revealed in their report.

\begin{tabular}{|c|c|c|c|c|c|c|c|c|c|}
\hline \multirow[t]{2}{*}{ Plant } & \multirow[t]{2}{*}{ Technology } & \multirow[t]{2}{*}{ Feedstock } & \multirow{2}{*}{$\begin{array}{l}\text { Fuel } \\
\text { capacity } \\
\text { (MW) }\end{array}$} & \multirow{2}{*}{$\begin{array}{l}\text { Electric } \\
\text { output } \\
\text { capacity } \\
\left(\mathrm{MW}_{\mathrm{e}}\right)\end{array}$} & \multicolumn{5}{|c|}{ Gas composition (vol\%) } \\
\hline & & & & & $\mathrm{CO}_{2}$ & $\mathbf{N}_{2}$ & $\mathrm{CO}$ & $\mathbf{H}_{2}$ & $\mathrm{CH}_{4}$ \\
\hline $\begin{array}{l}\text { Greve-in- } \\
\text { Chianti, } \\
\text { Italy [68] }\end{array}$ & CFB & $\mathrm{RDF}$ & $2 \times 15$ & 6.7 & 15.65 & 45.83 & 8.79 & 8.61 & 6.51 \\
\hline $\begin{array}{l}\text { Kymiarvi, } \\
\text { Finland [72] }\end{array}$ & CFB cofiring & $\begin{array}{l}\text { Recycled fuel mixture } \\
\text { (wood, board, paper, } \\
\text { plastic, RDF etc.) }\end{array}$ & 70 & 20 & 12.3 & 33.1 & 9.6 & 6.7 & 3.3 \\
\hline $\begin{array}{l}\text { Värnamo, } \\
\text { Sweden [68] }\end{array}$ & $\begin{array}{l}\text { - Integrated } \\
\text { gasification } \\
\text { combined cycle } \\
\text { (IGCC) }\end{array}$ & $\begin{array}{l}\text { Woodchips, pelletised } \\
\text { wood, bark, straw, RDF }\end{array}$ & 18 & 6 & 15.95 & 50 & 18 & 10.75 & 6.65 \\
\hline $\begin{array}{l}\text { Vermont } \\
\text { SilvaGas, USA } \\
{[69]}\end{array}$ & Indirect CFB & $\begin{array}{l}\text { Whole tree chips, } \\
\text { residue wood, } \\
\text { reconstituted wood } \\
\text { pellets, forest thinning }\end{array}$ & 44 & 9 & 12.2 & & 44.4 & 22 & 15.6 \\
\hline $\begin{array}{l}\text { Viking DTU, } \\
\text { Denmark [68] }\end{array}$ & $\begin{array}{l}\text { Two-stage fixed } \\
\text { bed }\end{array}$ & $\begin{array}{l}\text { Woodchips } \\
\text { (45\% moisture) }\end{array}$ & 70 & $\begin{array}{l}0.0175 \\
\left(39 \mathrm{MW}_{\mathrm{th}}\right)\end{array}$ & 15.4 & 33.3 & 19.6 & 30.5 & 1.2 \\
\hline
\end{tabular}

Table 2. Selected large-scale gasification plants and their gas compositions.

On $\mathrm{H}_{2}$, it is quite obvious that the Viking DTU [68] and Vermont SilvaGas [69] plants produce more than typical plants, at 30.5 and 22\%, respectively. Most other plants listed in Table 2 produce $\mathrm{H}_{2}$ at around 6-10\%. With advanced technology, more $\mathrm{H}_{2}$ can be produced though more costly; but high $\mathrm{H}_{2}$ may be preferred for several reasons: cleaner, high energy content (141.8 MJ $/ \mathrm{kg}$ for $\mathrm{H}_{2}$ as compared to $10.2 \mathrm{MJ} / \mathrm{kg}$ for $\mathrm{CO}$ ), and it is sold in the market at relatively higher price for various industrial applications. As in most gasification processes, $\mathrm{CH}_{4}$ tends to be in the lowest amount among the three production fuel gases. According to Table 2, they are typically less than $7 \%$ except for the Vermont SilvaGas [69] plant, for which the composition reported was $15.6 \%$. Like $\mathrm{H}_{2}, \mathrm{CH}_{4}$ is also regarded as valuable a gas; but the amount produced from gasification is usually low. 
Though not combustible, the amount of $\mathrm{CO}_{2}$ generated is also an interest because it is a greenhouse gas that contributes to global warming. Typically, the $\mathrm{CO}_{2}$ amount shown in Table 2 is consistent within $12-16 \%$ for all plants. More importantly, the $\mathrm{CO}_{2}$ released to the environment from biomass gasification could be offset by the amount absorbed by plants; presently this is the constant affirmation on why biomass is regarded as a source of renewable energy. Finally, it is worth noting that the Vermont SilvaGas [69] plant was developed based the outcome from a pilot plant, which was far smaller in scale. Interestingly, it was found that the gas compositions from the large-scale plant were almost the same with those of the pilotscale plant. The energy content dropped $6 \%$ from $18.5 \mathrm{MJ} / \mathrm{Nm}^{3}$ (pilot) to $17.3 \mathrm{MJ} / \mathrm{Nm}^{3}$. The $\mathrm{H}_{2}$ composition increased in the large-scale plant by $11 \%$, while CO decreased by $26 \%$; and there was almost no change for $\mathrm{CH}_{4}$. This implies that scaling up of biomass gasification plant may result in small impact on the gas composition and energy content.

\section{Gasification gas in CI engines}

Amongst the options for energy conversion, only those that produce gasification gas suitable for use in a CI engine are the main focus of this part. Fluctuation of the gasification gas constituents makes it not suitable for stable combustion in SI engine at high load cases. Gasification gases can be utilized as diesel replacement in CI engine in the dual-fuelling mode. However, not all types of diesel engines can be operated on the dual-fuel mode. For example, the use of gasification gas in compression ratios of ante-chamber and turbulence chamber CI engines prospects to knocking and ignition delay caused by too high pressures [70]. The conversion of DI CI engines can normally be done due to their lower compression ratios. The conversion of an engine to operate on dual-fuel mode of operation will generally prospect to lower power output. In order to minimize the power loss, the heating value of air-gas mixture should be increased. In addition, the amount of combustible mixture should be increased by applying a supercharging or a turbocharging technique on the engine. Furthermore, adjusting some operating parameters including increasing of compression ratio and advancing the injection timing might be another solution to minimize the power loss. The limitation of dual fuelling in CI engines is that without having a supply of ignition source like diesel fuel, it cannot be run. Furthermore, overheating of the pilot fuel injection jet might be occurred when the flow of diesel fuel reach a lower level of up to 10 or $15 \%$ of its normal flow. Therefore, the injector nozzle should be checked regularly after 500 hours of dual-fuelling operation as recommended by Von Mitzlaff [71].

\subsection{Fuelling strategy}

In dual-fuel operation, the supply of pilot fuel (diesel) from injection system is similar to the ordinary diesel mode of operation. An air-gas mixture prepared outside the combustion chamber in an external mixing chamber in the intake system is then sucked, compressed and ignited into the engine with the diesel fuel sprayed. The mixing device should have the capacity to provide a homogeneous air-gas mixture. There are several options for mixing devices as 
classified by Von Mitzlaff [71]. The type of mixers and their properties are summarized in Table 3.

According to the Turner and Weaver [74] the best and economic way to introduce gasification gas into dual-fuel engine is the central point mixing system.

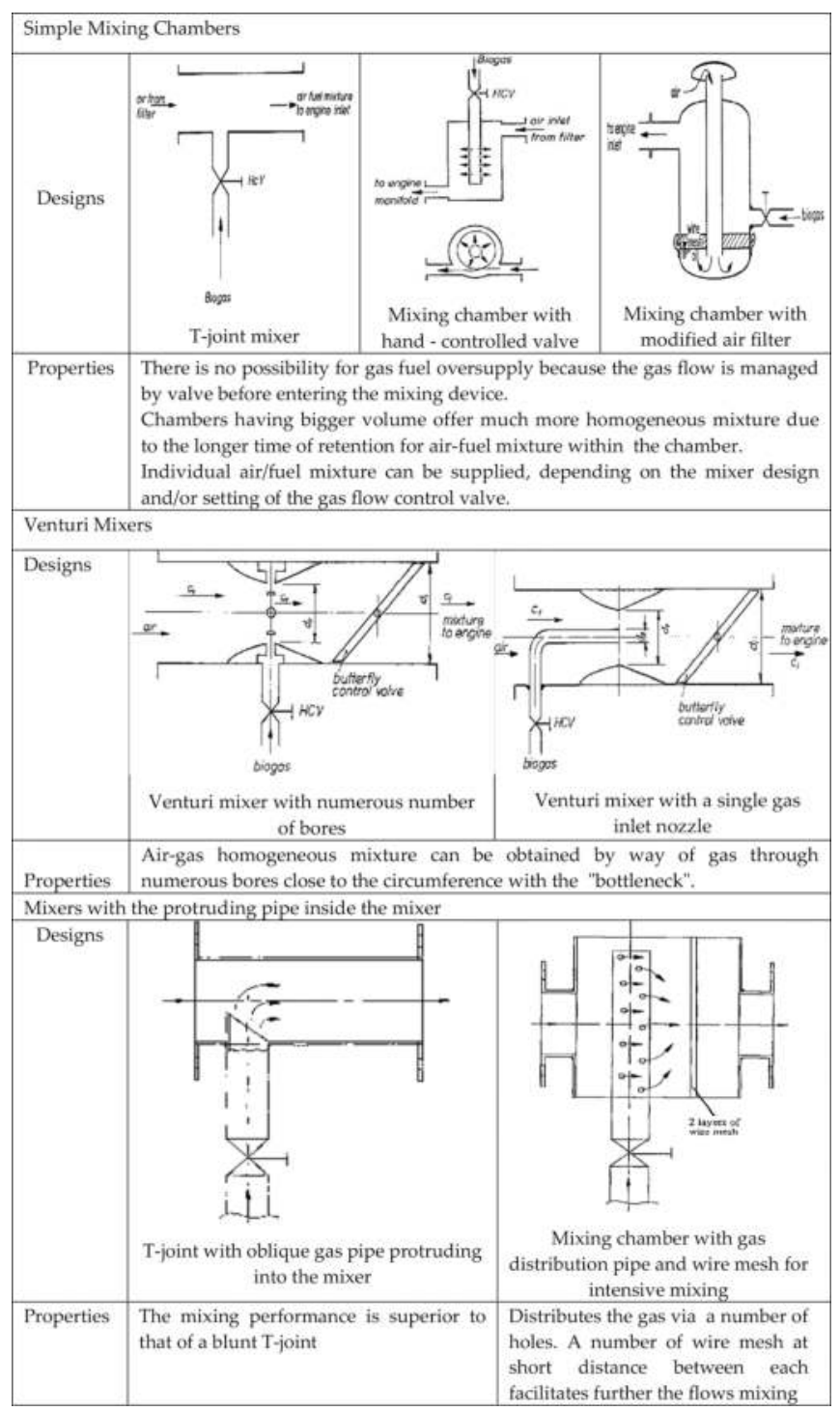

Table 3. The list of different mixer designs and their respective properties [73]. 


\subsection{Comparison of gasification gas and other renewable fuels in duel fuelling}

Different types of gaseous fuels were investigated with the intention of transiting from the fossil-dominated energy to biobased energy in both the CI and SI engines. Dual-fuel engines typically use either gasification gas, $\mathrm{H}_{2}, \mathrm{CNG}$, liquefied petroleum gas (LPG) or sometimes biogases as the primary fuel [75-79]. Gasification gases from different sources have been used in dual-fuel engines in order to investigate the impact of their composition and some operating parameters including load, injection timing and the air intake condition on dualfuel combustion. A study was conducted by Ramadhas et al. [80] on dual-fuelling combustion with rubber seed oil and coir-pith producer gas at distinctive load conditions and compared the performance results with normal diesel. Higher particular energy consumption at all load conditions was reported. A simulated gasification gas containing $49 \% \mathrm{~N}_{2}$, $12 \% \mathrm{CO}_{2}, 25 \% \mathrm{CO}, 10 \% \mathrm{H}_{2}$ and $4 \% \mathrm{CH}_{4}$ was used in dual-fuel $\mathrm{CI}$ engine at a speed of 2000 rpm. The result has indicated poor combustion efficiency of gasification gas dual fuelling compared to normal diesel operation. The poor combustion was due to the lower heating value of used gasification gas $(7444.13 \mathrm{~kJ} / \mathrm{kg})$ compared to diesel, or either due to a too lean mixture or a too rich mixture [81]. Sahoo et al. [51] have made an attempt to improve dualfuelling combustion by varying the engine load. Substandard engine performance was revealed at light loads for dual-fuel operation. However, an improvement on the thermal efficiency was recorded over half load for dual-fuel mode of operation. In order to improve the poor combustion efficiency with the gasification gas fuelling in dual-fuelling strategy, Roy et al. [82] have investigated the influence of intake pressure (101-200 kPa) in order to improve dual-fuel combustion by supercharging a pyrolysis gas engine with micro-pilot ignition. It was concluded that greatest indicated mean effective pressure (IMEP) was attained with an intake pressure of $200 \mathrm{kPa}$, and the thermal efficiency was also improved.

Numerous investigations were conducted by the researchers as to provide information on the effect of composition of gasification gas on dual-fuel combustion when combusted in CI engines [82, 83]. Most of them concluded that increased hydrogen content of the gasification gas affects positively on the combustion efficiency. In the study by Roy et al. [82], higher thermal efficiency of $37-38 \%$ was attained with the use of the $20 \% \mathrm{H}_{2}$ content gasification gas rather than the $13.7 \% \mathrm{H}_{2}$ content. The dual-fuel engine was able to work with wider window of fuelair equivalence ratio $(0.42-0.79)$. The $20 \% \mathrm{H}_{2}$ content producer gas also shorten the combustion duration by 4 to $5^{\circ} \mathrm{CA}$. The engine used by Tomita et al. [83] has functioned steadily with stable combustion and enhanced efficiency with the increase of hydrogen content in syngas, even at an equivalence ratio of $\varphi=0.45$ because the more hydrogen content enhances the limit of lean mixture. Further, $12 \%$ greater power was attained when higher hydrogen content gasification gas was used by Roy et al. [82] in dual-fuel engine with the application of exhaust gas recirculation (EGR) in syngas emitted from hydrogen-rich coke-oven gas.

Besides the gasification gas, there are many reports on research regarding dual fuelling in CI engine with other renewable fuels. The usage of port fuel-injected natural gas and DI diesel generally results in a significantly increased fuel consumption compared to the conventional diesel operation as reported in the work by Papagiannakis and Hountalas [84]. Saleh, and many others, revealed that duel-fuel combustion with LPG (port fuel injection [PFI]) and diesel does 
not have a significant influence on the efficiency of an engine [85]. For hydrogen dual fuelling, the efficiency of a dual-fuel engine tends to increase while running on hydrogen and diesel as revealed from different studies by Saravanan et al. [86-88]. An increased efficiency was also observed when dual-fuel engine was operated by Azimov et al. [89] with natural gas and syngas under premixed mixture ignition in the end-gas region (PREMIER) combustion mode and supercharging condition. However, the research carried out by Bika et al. [90] shows reduced efficiencies in dual-fuel mode.

In summary, a complete replacement of diesel fuel with gasification gas could not be possible. Besides, the performance of such dual fuelling of gasification gas and diesel was poorer as compared to dual fuelling of other renewables. However, a compromise among improved efficiency and reduced exhaust emissions might be achieved if gasification gas with increased hydrogen content is used in dual-fuel engines with maintained operating conditions. Moreover, it can be used as a supplementary fuel to reduce cost and emissions of $\mathrm{NO}_{x}$ and particulate matter. In comparison between different renewable gases, hydrogen and natural gas seem to show slight increase on the engine efficiency when compared to syngas and natural gas. Natural gas and synthesis gas seem to be used for greener options to replace fossil fuels in internal combustion engines [91-93].

\subsection{Combustion process of dual fuelling}

The typical dual-fuel combustion consists of three stages, premixed combustion with the direct-injected diesel fuel in addition to a minor portion of the gasification gas entrained within the diesel spray. The second stage is characterized by the premixed combustion of the major portion of the gasification gas in addition to tiny amounts of the diesel. Finally, the diffusion combustion of the rest of the two fuels represents the third stage. Figure 1 shows the main three phases of dual-fuel combustion.

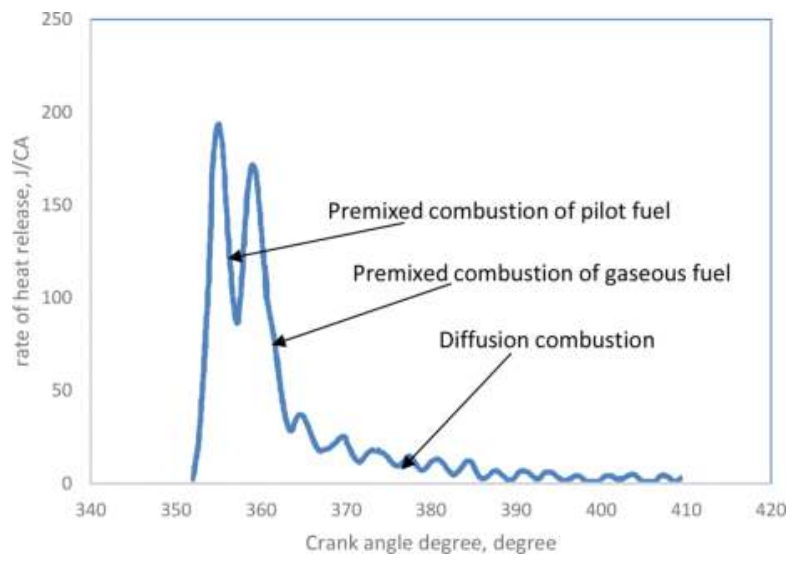

Figure 1. Rate of heat release (ROHR) for "conventional" dual fuel combustion [94]. 
The amount of diesel substituted by gasification gas is very important in order to characterize the first two stages. However, the amount of pilot fuel that can be burned during this stage has significant effect on the peak rate of heat release (ROHR). The importance of this phase decreases only once the level of pilot fuel is decreased under this specific limit. The significance of the second phase alternatively is determined through the quantity of diesel substitution. The advantage of this concept is that it makes use of the difference in flammability of the used fuels. When leaving out the gaseous fuel, the engine operates as a normal diesel engine. However, since the liquid diesel is necessary for ignition, it is not possible to run it exclusively on the gaseous fuel.

\subsection{Changes in pollutant emissions as a result of using gasification gas}

A number of researchers have concluded that gasification gas dual fuelling is considered a promising technique for controlling $\mathrm{NO}_{x}$ emissions and smoke [95-97]. Lower particulate matter (PM) might be achieved by utilizing a lean air-gas mixture in dual-fuel engine rather than normal ordinary diesel only. Existing dual-fuel conversions endure from significant increases in $\mathrm{CO}$ and unburned hydrocarbon (UHC) emissions at low engine loads due to the very lean combustion at light loads. As the combustion gets leaner, the combustion directly degrades, leaving massive quantities of partial reaction items during the exhaust. Figure 2 shows that the gasification gas used by Mahgoub et al. [81] has the possibility of reducing the level of $\mathrm{CO}_{2}$ and $\mathrm{NO}_{x}$ emissions compared with diesel fuel when operated on a naturally aspirated, two stroke, single cylinder, diesel engine at a speed of $2000 \mathrm{rpm}$.
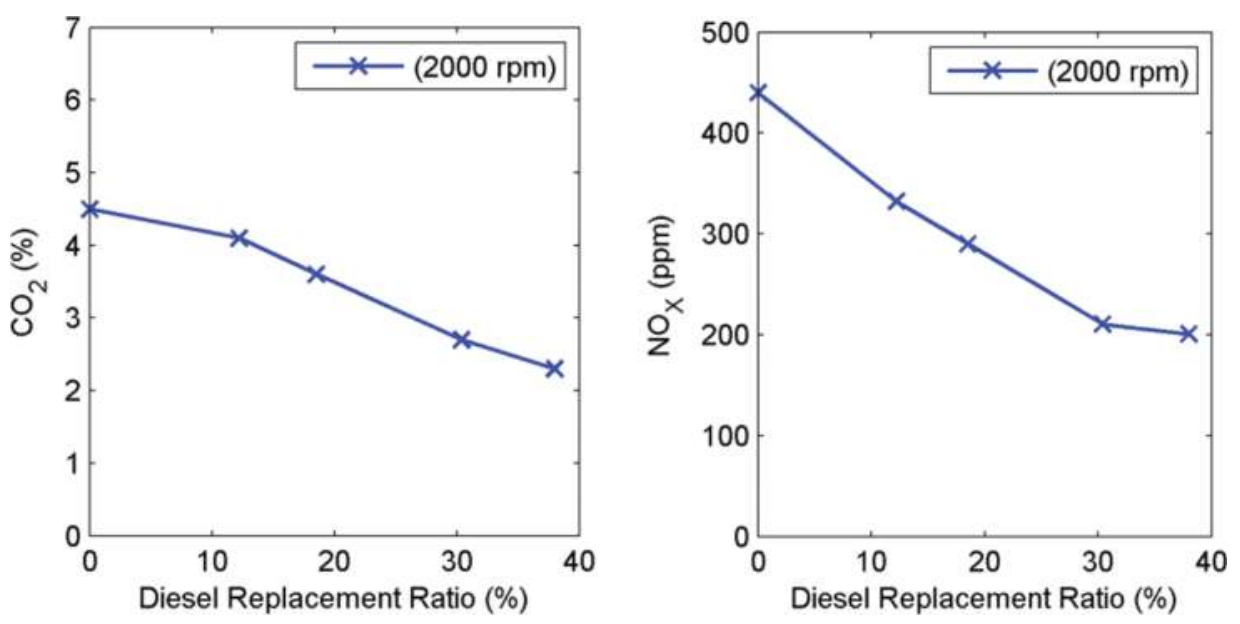

Figure 2. $\mathrm{CO}_{2}$ and $\mathrm{NO}_{x}$ concentration versus diesel replacement ratio (syngas dual fuelling) [81]. 


\section{Gasification gas in spark ignition engines}

\subsection{Fuelling strategy}

As it is explained in Section 1, the history of gasification gas in the automotive engines is associated with the naturally aspirated SI-carburettor-type engines. Carburetted and portinjection engines mix the fuel and air prior to the combustion chamber and the volumetric efficiency of the engine drops at the cost of the voluminous gasification gas displacing air. Furthermore, they have higher pumping and heat losses as compared to DI SI engines, resulting in high fuel consumption [98]. Consequently, the theoretical power output of gasification gases fuelled carburetted and port-injection engines is lower than those of their DI engine counterparts and gasoline and CNG fuelled in the same arrangement.

With the emergence of DI application in SI engines, lean combustion strategy has become a means for the reduction of greenhouse gas emissions and in increasing thermal efficiency. This strategy is mainly accompanied with fuel stratification so that variable air-fuel ratio occurred around the combustion chamber. The stratification provides a relatively rich mixture near the igniter and a uniformly mixed ultra-lean mixture all over the cylinder. Engine performance reduction due to volumetric efficiency drop can also be overcome by injecting the fuel very late after inlet valve close (IVC). However, this may lead to insufficient time for fuel-air mixing and slow combustion rate. For the fast burning type fuels, this is the type of fuel injection strategy that has been adopted and it has attracted much attention these days. The $\mathrm{H}_{2}$ component of the gasification gases, mainly the medium calorific value gasification gases, is grouped in the fast-burning-type fuels. Therefore, irrespective of the other engine operating parameters, gasification gas fuelled engine with a DI system is expected to have better engine power output. Similar hypothesis is implied by other researchers too [99]. In this section, a DI SI engine under the stratified charge strategy is preferred as a fuelling system for a two typical gasification gas representative mixtures from both the lower and medium calorific value fuels. The detailed characteristics of these two mixtures are presented in Table 1. The experiment was conducted in a single cylinder engine with a compression ratio of 14 and a displacement volume of 399.25 cc. Detailed engine specification can be referred from [55, 56]. The two representative gasification gases are premixed from their respective constituent gases based on their molar ratio and stored in bottles at a pressure of 140 bar.

\subsection{Combustion process of gasification gases in SI engines}

Investigation of the in-cylinder combustion by monitoring the pressure data with the help of a pressure sensor was performed. A piezoelectric pressure transducer was used to collect the pressure data. Pressure reading of up to 100 power cycles was recorded and a macro code is developed to analyze the combustion characteristics from the data and further to select the most representative cycle of the average cycle. Further analysis of the pressure data resulted in mean effective pressure (IMEP), rate of pressure rise, heat release rate and mass fraction burn (MFB). The performance and emissions of the gases fuelled in DI SI engine was also investigated. The fact that the gas composition, calorific value and the stoichiometric air-fuel 
ratio of the gases are different, comparison of the two gases at the same operation conditions is impossible.

\subsubsection{Lower calorific value gasification gas combustion}

Figure 3 shows the variation of pressure, heat release rate and MFB with engine crank angle (CA) at different speeds ranging from 1800 to $2400 \mathrm{rev} / \mathrm{min}$ for the lower calorific value gasification gas. These combustion characteristics are presented for IMEP of 2.7 bar attained at $\lambda=4.93,4.97$ and 5.46 for engine speeds 1800,2100 and $2400 \mathrm{rev} / \mathrm{min}$, respectively. Table 4 shows the air-fuel ratio, ignition advance and combustion durations of different engine speeds of the lower calorific value gasification gas operation at IMEP $=2.7$ bar.
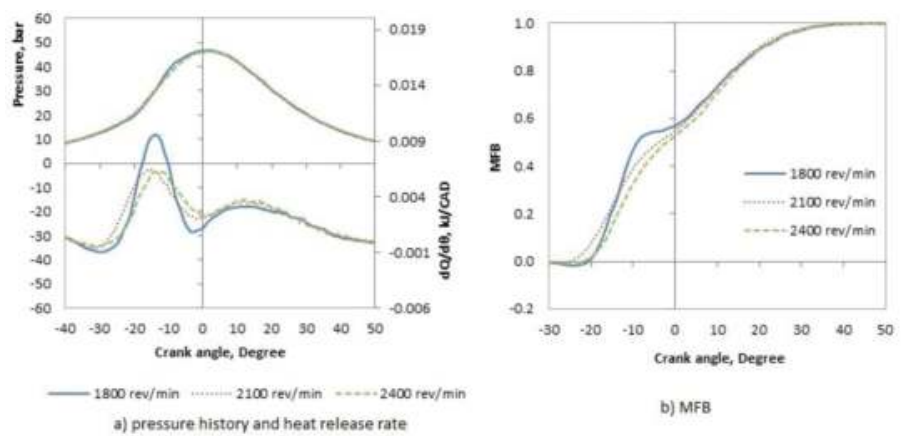

Figure 3. Combustion characteristics versus crank angle for 1800,2100 , and $2400 \mathrm{rev} / \mathrm{min}$ at IMEP $=2.7 \mathrm{bar}$.

\begin{tabular}{llll}
\hline Speed (rev/min) & 1800 & 2100 & 2400 \\
$\lambda$ & 2.42 & 2.60 & 2.61 \\
Ignition advance $\left({ }^{\circ} \mathrm{BTDC}\right)$ & 31 & 31 & 31 \\
Flamed development stage duration $\left({ }^{\circ} \mathrm{CA}\right)$ & 13 & 12 & 15 \\
Rapid burning stage duration $\left({ }^{\circ} \mathrm{CA}\right)$ & 38 & 39 & 37 \\
Overall combustion duration $\left({ }^{\circ} \mathrm{CA}\right)$ & 51 & 51 & 52 \\
\hline
\end{tabular}

Table 4. $\lambda$, ignition advance and combustion durations of different speeds and IMEP $=2.7$ bar.

The pressure profile presented the same curve for all speeds with its peak value of 47 bar at TDC. However, the heat release rate was shown to experience different trend for all the speeds mentioned. The fastest and shortest heat release rate was observed with the lowest engine speed. Both engine speeds at 2100 and $2400 \mathrm{rev} / \mathrm{min}$ were shown to experience similar heat release rate profile except for the position of the peak heat release rate. The position of the peak heat release rate was shown to retard with the highest speed. Both engine speeds experienced decreasing trend of heat release rate at around $5^{\circ} \mathrm{CA}$ before top dead centre (BTDC) and then 
started increasing until another peak was observed at $12^{\circ} \mathrm{CA}$ after top dead centre (ATDC) as shown Figure 3(a). This was attributed to heat transfer to the cylinder walls as the result of increased heat transfer area. Majority of the chemical energy was converted to heat before the piston reached its TDC. However, the surface area of the chamber is larger than that of at TDC at this position. The MFB curve in Figure 3(b) was observed to deviate from the well-known S-shaped curve, where there was a plateau shape of around $50-70 \%$ of MFB for all operation speeds. The ignition advance was set to be at the maximum brake torque (MBT) attained at $31^{\circ} \mathrm{CA}$ BTDC in both conditions as shown in Table 4 . As a result, the maximum rate of pressure rise was recorded at around $15^{\circ} \mathrm{CA} \mathrm{BTDC}$ on average for all operation conditions. Similarly, the heat release rate was also maximum in this crank angle position. However, the surface area of the chamber was higher at this crank angle position compared to TDC. Due to this, there was higher heat loss through the chamber walls and this could be witnessed from the heat release rate curves as shown in Figure 3(a). In addition, the fuel produced a very low IMEP. The shape could also be due to a very weak mixture energy density in the cylinder. The flame generated through the combustion of this fuel was very weak in all operational conditions. Even though the flame was sustained throughout the cycle, there could be a chance of flame quenching during the period of high heat loss and high turbulence in the combustion chamber during the compression stage. A detailed analysis of the behaviour of such double-Wiebe of the MFB is presented in the article by Hagos and Aziz [56].

As such low calorific value fuels have not been studied in DI SI engine, and the results of this research could not be compared with previous works. However, the MFB curve shown in Figure 3(b) was different from the ones reported for carburetted SI engine elsewhere [44, 100], where a low calorific value gas (producer gas) of similar composition was fuelled in a carburetted naturally aspirated SI engine. This could be due to the reason that the previous works operated the engine at homogeneous mixture condition. This fuel was shown to experience technical difficulties in DI engine due to the injection duration limitation. The performance and emission gains thought from the DI fuelling were much overshadowed by the restriction of injection duration. However, the unique nature of the combustion parameters of this fuel attracted more attention. The double-Wiebe function of the MFB of this fuel could be an input in the study of in-cylinder combustion of other multi-species fuels.

\subsubsection{Medium calorific value gasification gas combustion ( $\left.50 \% \mathrm{H}_{2}-50 \% \mathrm{CO}\right)$}

The medium calorific value gasification gas was investigated in the DI SI engine for the combustion, performance and emissions for the engine speed ranging from 1500 to $2400 \mathrm{rev} /$ min. The operation parameters studied are the effect of engine speed and injection timing and further the combustion, performance and emissions was compared with that of CNG. The two injection timings investigated are $120^{\circ} \mathrm{BTDC}$ that represent the direction injection where fuel is started to be injected after the inlet valve closes and $180^{\circ}$ BTDC representing partial direct injection where fuel is started to be injected before the inlet valve closes. Late injection timings below $120^{\circ}$ BTDC and early injection above $180^{\circ}$ BTDC was found not suitable for such fuels due to longer injection duration demand and volumetric efficiency concerns, respectively. Both the two injection timings have their advantages with the late injection suitable for lower engine 
speed and the early injection suiting the high engine operation speed. Details of the study are presented elsewhere [101].
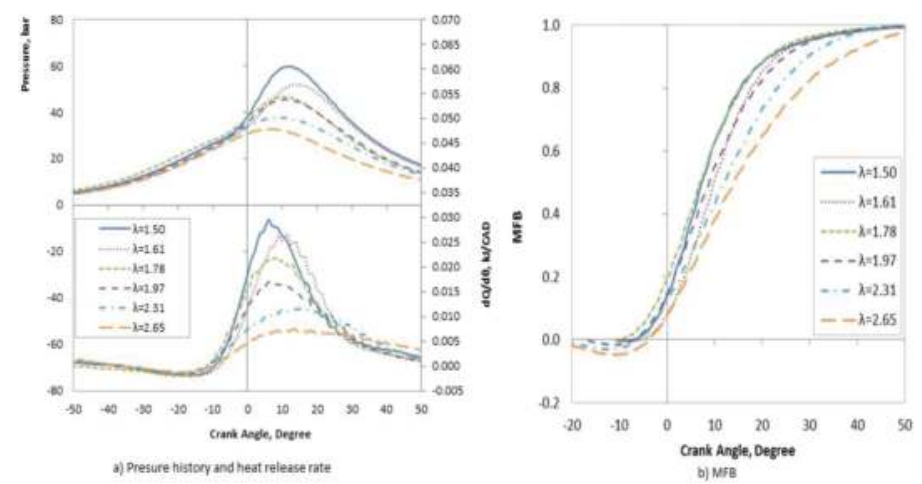

Figure 4. Cylinder pressure heat release rate and MFB versus crank angle for different $\lambda$ and at $180^{\circ}$ BTDC and 2100 $\mathrm{rev} / \mathrm{min}$.

Figure 4 shows the effect of the air-fuel ratio on the pressure profile, heat release rate and MFB for different $\lambda$ at $2100 \mathrm{rev} / \mathrm{min}$. The ignition advance was set at MBT and the injection timing at $180^{\circ} \mathrm{CA}$ BTDC. Figure 4 (a) shows the variation of pressure profile and heat release rate with crank angle for various $\lambda$ at $2100 \mathrm{rev} / \mathrm{min}$. The peak in-cylinder pressure was shown to decrease with an increase in $\lambda$. The crank angle corresponding to the peak in-cylinder pressure was observed to advance except at $\lambda=1.61$. The fastest and shortest heat release rate was presented at the lowest $\lambda$. The slowest and longest heat release rate was observed with the highest $\lambda$. The combustion phenomenon in Figure 4(a) could be further discussed with the cumulative heat release curve (MFB) as shown in Figure 4(b). The overall combustion angle was shown to increase with an increase in $\lambda$. This was attributed to the mixture energy density in the chamber. Higher energy density generated more heat leading to higher in-cylinder temperature and thereby fast combustion. The effect of change in the air-fuel ratio on MFB was more evident at the initial stage of combustion for the lower speeds (1500 rev/min) while at the rapid burning stage for the higher speed (2100 rev/min). However, at $2100 \mathrm{rev} / \mathrm{min}$ the effect of air-fuel ratio on MFB was visible on the rapid burning stage. This is due to an increase in turbulence as a result of increased speed. This would speed up the combustion rate mainly at the rapid burning stage [58].

On the analysis of the variation of ignition advance with the air-fuel ratio, it was observed that the start of ignition for maximum brake torque was advanced with an increase in $\lambda$ at all operation speeds. Similarly, the trend of flame development, rapid burning stage and overall combustion durations were shown to increase with an increase in $\lambda$. The combustion duration is also observed to increase with an increase in the engine speed. Details about the effect of the air-fuel ratio and the engine speed on the combustion characteristics in the DI SI engine are reported in Hagos et al. [58]. 


\subsection{Comparison of gasification gas and other renewable fuels}

Comparison of the combustion and performance of the medium calorific value gasification gas with CNG was conducted under the same engine atmosphere and the study is presented in a separate article [55]. The gasification gas was shown to have a higher peak cylinder pressure, higher heat release rate and faster combustion duration than CNG at all operation speeds and loads. This was attributed to the fast flame propagation of the hydrogen species in the syngas fuel. On the other hand, the ignition advance for MBT was retarded with the gasification gas compared to CNG. This was because of the longer injection duration with gasification gas compared to that with CNG. The fast flame-propagation nature of the $\mathrm{H}_{2}$ species in the gasification gas resulted in a shorter ignition delay and also contributed in the retardation of the ignition onset of the syngas. The performance comparison of the two fuels, however, has resulted in lower brake thermal efficiency and higher brake-specific fuel consumption (BSFC) of the gasification was reported which was more pronounced at lower engine loads. With increasing speed, the difference was decreased. This was mainly attributed to the low calorific value nature of the gasification gas [55].

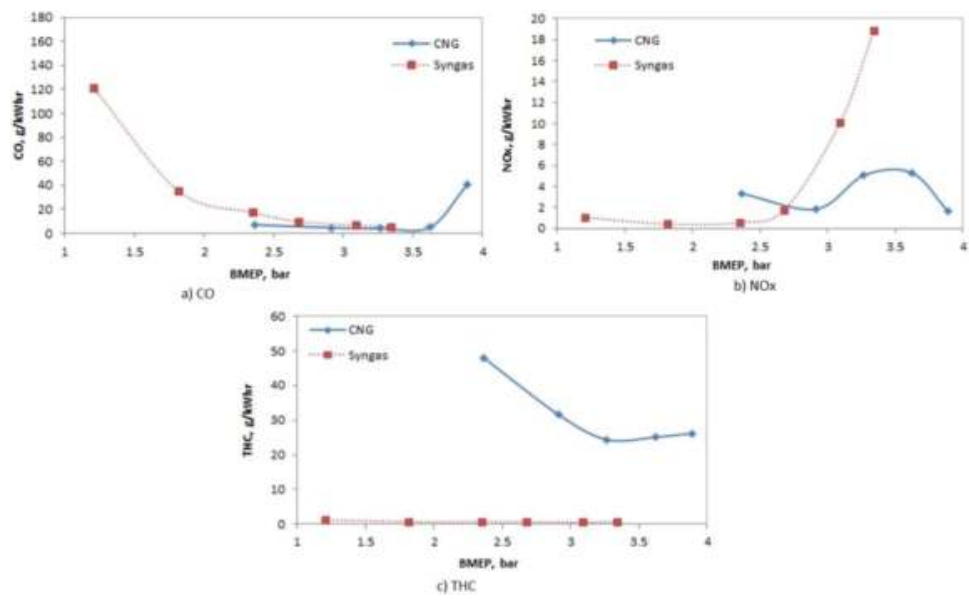

Figure 5. Brake-specific emissions versus BMEP for medium calorific value gasification gas and CNG at $2100 \mathrm{rev} / \mathrm{min}$ [55].

\subsection{Changes in pollutant emissions as a result of using gasification gas}

The major combustible components of the gasification gases are $\mathrm{H}_{2}, \mathrm{CO}$ and $\mathrm{CH}_{4}$. Due to this fact, the emission trends of such fuels in the direct-injection spark ignition engines are different as compared to that of fossil-based fuels. Figure 5 shows the brake-specific emissions of CO, $\mathrm{NO}_{x}$ and total hydrocarbons (THC) versus the brake mean effective pressure (BMEP) of the medium calorific value gasification gas (syngas). Only the engine speed of $2100 \mathrm{rev} / \mathrm{min}$ is considered for the comparison of the gasification gas with that of CNG. The fact that heavy hydrocarbons are absent in the gasification gases indicates that the total hydrocarbon emis- 
sions are insignificant in the combustion of gasification gases in IC engines. On the other hand, the presence of $\mathrm{H}_{2}$ in the gasification gas leads to rapid combustion and higher peak in cylinder pressure. As a result, the $\mathrm{NO}_{x}$ emission was observed to be higher with the gasification gases even if the fuelling strategy is at lean and stratified charge. Similarly, the CO emissions with gasification gases were slightly higher with gasification gases as compared to CNG at lean operation. This is attributed to the incomplete combustion due to lower mixture energy density with lean mixture and escaping of the natural $\mathrm{CO}$ of the fuels unburnt from the combustion chamber.

\section{Safety of gasification gases}

Gasification gases are flammable fuels similar to any other fuels. Table 1 shows the range of flammability limits of gasification gases, $\mathrm{CNG}$ and $\mathrm{H}_{2}$. Flammability limit is very important characteristics in the safety of fuels in IC engines. Liquid and some gaseous fuels that are commonly used in the automotive engines have been through safety tests during their refuelling, recharging and in crash conditions. Based on the extensive tests, these common fuels are supported with safety codes. For gaseous automotive fuels such as CNG, Vehicular Gaseous Fuel Systems Code (NFPA52) is a code used to govern for their fuelling facility [102]. Alternative fuels that are aimed to replace or take part in the fuelling of automotive engines need to undergo similar safety tests. For the gasification gas fuels, there is limited research towards safety. Besides the flammability issue, the $\mathrm{CO}$ content of the gasification gas needs to be taken into consideration. The fact that $\mathrm{CO}$ is toxic gas indicates that the utilization of such fuels needs to be under a very tight condition to avoid CO contamination. On the other hand, to compensate the calorific value and increase the mileage at once charging, gasification gas needs to be compressed at high pressure in the range of 200-300 bar. This will require different safety issues that need further consideration. Similar to CNG, these gasification gases are colourless, odourless and tasteless. Therefore, their leakage may not be easily detected. Therefore, odorants should be intentionally added for the easy detection. In general, fire safety issue of gasification gases in IC engines should be adequately addressed in the development and research stage.

\section{Technical challenges}

The main technical challenge in the fuelling of gasification gas in ICE is the tar deposition in the combustion chamber. Even though ICE is more tolerant towards contaminants compared to gas turbines, the level of tar in the gasification if proper cleaning system is not installed would lead to frequent breakdown. Such challenge could be even worst in the direct-injection engines as injection nozzle hole diameter is too small. The deposition of contaminants and thereby blockage of injector nozzle is imminent in such engines. The molar fraction of the constituent gases varies depending on the variation of the operation conditions for syngas produced from gasification. Maintaining its consistency is huge challenge. The molar fraction 
is responsible for the most of fuel properties of the gasification gas, mainly the calorific value, air-fuel ratio, laminar flame speed, auto ignition temperature and the flammability limit. The parameters on the other hand affect the combustion behaviour of the fuel. Similar concern is also present on the fuelling and/or blending of gasification gas in gas turbine plants. Similar feedback system developed for the gas turbine plants may be customized for ICE fuelled by varying molar fraction gasification gases.

The lower calorific value of gasification gas as compared to other gaseous and liquid fuels is another technical challenge that requires precise emphasis in the ICE fuelling. Fuelling of lower calorific value gaseous fuels in the direct-injection spark ignition engine leads for the demand of longer injection duration for the fuels to be fully inducted into the combustion chamber. This is difficult especially during operation at near stoichiometric operation and when the engine speed is higher than $1800 \mathrm{rev} / \mathrm{min}$. Therefore, the utilization of such lower calorific value gaseous fuels in the direct-injection spark ignition engines is possible at lean fuelling strategy. On the other hand, the application of such fuels leads to higher BSFC in the ICE. This has its own consequence on the fuel storage system requiring high-pressure storage system. Methane enrichment of such fuels was used to tackle the challenge in the direct-injection spark ignition engine. As per preliminary study, improvements on the BSFC and on the limitation of the injection duration are observed [103]. Further study on the percentage of the enrichment is undergoing. Parallel to this, the safety issue of the utilization of these fuels in ICE needs to be studied as there is limited information. The $\mathrm{CO}$ content of the gasification gas is toxic and extra care need to be given mainly in the fuelling such gases in the carburetted and port-injected spark ignition engine and the dual-fuelling compression ignition engine.

The main motivation in using gasification gases and other gaseous fuels in diesel engine is for a possible substitution of diesel by gaseous fuel, thereby reducing cost, minimizing pollutant emissions such as $\mathrm{NO}_{x}$ and particulate matter, and further to increase the performance of the engine. The performance of a dual-fuel mode compression ignition engine running with gasification gas with composition of $10 \% \mathrm{H}_{2}, 25 \% \mathrm{CO}, 4 \% \mathrm{CH}_{4}, 12 \% \mathrm{CO}_{2}$ and $49 \% \mathrm{~N}_{2}$ and diesel as pilot fuel was compared with methane in the same duel fuel arrangement [48]. In both the fuels, a shift from diffusion flame combustion to propagation flame combustion was reported with the reduction of the pilot diesel fuel. Overall, methane was shown to perform better as compared to gasification gas in the duel fuelling mode for diesel substitution.

The production and storage process of gasification gases leads to the exposition of the gases to metals such as iron and nickel on the walls of the gasifier and storage tanks [14, 104, 105]. The contact of $\mathrm{CO}$ with these metals at higher pressure and temperature leads to the formation of metallic carbonyl contaminants such as iron pentacarbonyl $\left(\mathrm{Fe}(\mathrm{CO})_{5}\right)$ and nickel tetracarbonyl $\left(\mathrm{Ni}(\mathrm{CO})_{4}\right)$. At high temperature combustion, the metallic carbonyls, iron pentacarbonyl in particular, decomposes into metal oxide particles in the combustion chamber [106]. Figure 6 shows the deposits in the combustion chamber of the DI SI engine fuelled with gasification gas. Apart from the deposit formation and its physical effect on the engine components, these metallic carbonyls could also contribute on the formation of particulate matter emissions and flame inhibition $[14,104]$. Therefore, extra care should be given to the material in the design of syngas production and storage system. 


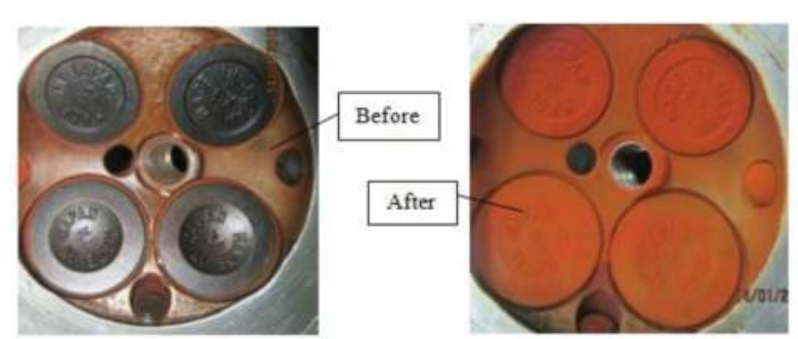

a) Valve seat and cylinder head before and after syngas fueling

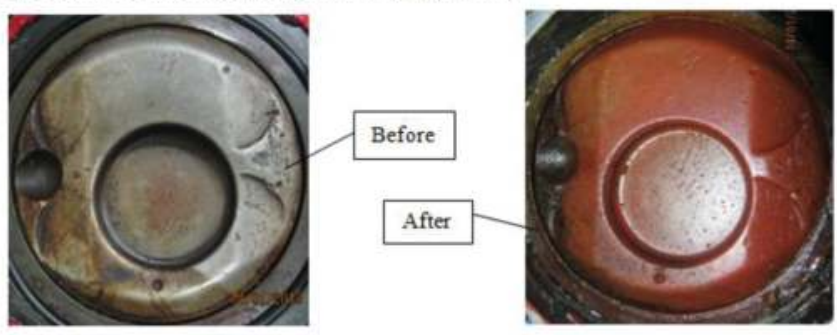

b) Piston head before and after syngas fueling

Figure 6. $(a$ and $b)$ Deposits of iron oxides in the combustion chamber of the SI DI engine fuelled with syngas [106].

\section{Conclusions and future research directions}

The prospect of gasification gas in the IC engines (both SI and CI) has been investigated by taking both the lower and medium calorific value gases into consideration. Due to the higher auto-ignition temperature of gasification gases, they are not suitable to utilize in the CI engine as lone fuels. Both lower and medium calorific value gasification gases have been utilized in a dual-fuelling CI engine with diesel as a pilot fuel for the initiation of the ignition. The amount of diesel as a pilot fuel not only affects the performance but also the combustion phenomenon in the dual fuelling, thereby the emissions of major pollutant gases. The fuelling system design influences the fuel mixing and the overall combustion process in the dual fuelling. The main fuel should be premixed and homogenized during the induction into the combustion chamber. Among the fuelling system designs, the central point mixing system is found compatible to gasification gas induction in the dual-fuelling mode operation. While the gasification gases have shown improvements in the emissions reduction, the higher calorific value gases such as $\mathrm{CNG}$ and $\mathrm{H}_{2}$ have better benefit in the diesel substitution and combustion stability under wider engine operation.

During the era of World War II, where aesthetic value and space conditioning were not an issue at all, gasification gases were utilized in the carburetted SI engine by directly coupling the gasifier with the engine in the vehicle. This design has served its purpose during the severe shortage of gasoline during the war. After the war, however, gasoline distribution came to 
normal and the development of vehicle designs channelled to gasoline's advantage. The major discouragements of the gasification gases were start ability, design complexity and inertia, power drop and operation problems. The advancements in the solid fuel conversion technologies and the development of large-scale power plants operating with gasification gases prompted for the application of storage system and thereby the separation of gasification plant from the power plant. This has further initiated the idea of utilizing the gasification gas in the SI DI engine. The medium calorific value gasification gases have shown promising result on the combustion stability and emissions reduction as compared to CNG with some limitations on the longer injection duration demand and higher BSFC. On the other hand, lower calorific value gasification gas is not found suitable for DI SI application. However, the combustion phenomenon observed with this fuel in the DI SI engine is unique and can be an interest to researchers to further investigate the combustion kinetics.

As a future direction, the two limitations stated in the previous paragraph for the medium calorific value gasification gas are found to have minimum effect with an enrichment of methane, thereby boasting the calorific value. However, the optimum percentage of methane enrichment has not been researched so far. The double-Wiebe function of the mass fraction burn of the combustion of lower calorific value gasification gas is another interest for further research. Finally, the safety concerns, the complete system energy balance and the potential to control the formation of deposits of metallic pentacarbonyls need to be further investigated.

\section{Nomenclature}

\begin{tabular}{ll}
\hline ATDC & after top dead centre \\
BMEP & brake mean effective pressure \\
BSFC & brake specific fuel consumption \\
BTDC & before top dead centre \\
CA & crank angle \\
CFB & Circulating fluidized bed \\
CI & compression ignition \\
CNG & compressed natural gas \\
CO & carbon monoxide \\
DI & direct injection \\
DME & Dimethyle ether \\
EGR & Exhaust gas recirculation \\
HC & hydrocarbon \\
ICE & internal combustion engine \\
IMEP & indicated mean effective pressure \\
IVC & inlet valve close \\
\hline
\end{tabular}




$\begin{array}{ll}\text { LPG } & \text { liquefied petroleum gas } \\ \text { MBT } & \text { maximum brake torque } \\ \text { MFB } & \text { mass fraction burn } \\ \text { NOx } & \text { nitrogen oxides } \\ \text { OECD } & \text { Organization for Economic Cooperation and Development } \\ \text { PFI } & \text { port fuel injection } \\ \text { PREMIER } & \text { premixed mixture ignition in the end-gas region } \\ \text { RDF } & \text { Refuse-derived fuel } \\ \text { ROHR } & \text { rate of heat release } \\ \text { rPm } & \text { revolutions per minute } \\ \text { SI } & \text { spark ignition } \\ \text { TDC } & \text { top dead centre } \\ \text { THC } & \text { total hydrocarbon } \\ \text { UHC } & \text { unburned hydrocarbon } \\ \lambda & \text { relative air fuel ratio }\end{array}$

\section{Author details}

Ftwi Yohaness Hagos ${ }^{1,2 *}$, Abd Rashid Abd Aziz ${ }^{3,4}$, Shaharin A. Sulaiman ${ }^{3,4}$ and Bahaaddein K. M. Mahgoub ${ }^{4}$

*Address all correspondence to: ftwi@ump.edu.my

1 Faculty of Mechanical Engineering, University of Malaysia Pahang, Pekan, Pahang, Malaysia 2 Automotive Engineering Center, University of Malaysia Pahang, Pekan, Pahang, Malaysia

3 Centre for Automotive Research and Electric Mobility (CAREM), Universiti Teknologi PETRONAS, Bandar Seri Iskandar, Tronoh, Perak, Malaysia

4 Department of Mechanical Engineering, Universiti Teknologi PETRONAS, Bandar Seri Iskandar, Tronoh, Perak, Malaysia

\section{References}

[1] J. B. Heywood, Internal Combustion Engine Fundamentals. New York: McGraw Hill International, 1988. 
[2] M. V. Melosi. "The automobile and the environment in American History", Automobile in American Life and Society, 2010 (August 12, 2014). Available at: http://www.autolife.umd.umich.edu/Environment/E_Overview/E_Overview3.htm

[3] K. D. Decker. Wood Gas Vehicles: Firewood in the Fuel Tank, 2010 (October 15). Available at: http://www.lowtechmagazine.com/2010/01/wood-gas-cars.html

[4] J. Dulac, "Global transport outlook to 2050: Targets and scenarios for a low-carbon transport sector", ed. EGRD, OECD/IEA, International Energy Agency, 2012.

[5] D. o. E. a. S. Affairs, "World population projected to reach 9.6 billion by 2050", in UN News, New York: United Nations, 2013.

[6] S. Watson, L. Fulton, S. Perkins, and R. de Jong, "50 by 50: Global Fuel Economy Initiative", 2009. Available at: http://www.fiafoundation.org/50by50/documents/ 50BY50_report.pdf

[7] S. R. James, "Hominid use of fire in the lower and middle Pleistocene: a review of the evidence", Curr. Anthropol., vol. 30, pp. 1-26, 1989.

[8] D. Tillman, The Combustion of Solid Fuels and Wastes. London, UK: Academic Press, 1991.

[9] R. Kandiyoti, A. Herod, and K. Bartle, Solid Fuels and Heavy Hydrocarbons Liquids: Thermal Characterization and Analysis. Amsterdam, The Netherlands: Elsevier, 2006.

[10] M. Lackner, Á. Palotás, and F. Winter, Combustion: From Basics to Applications. Weinheim, Germany: Wiley Publisher, 2013.

[11] WEC. World Energy Resources: 2013 Survey [Online]. Available: http://www.worldenergy.org/data/resources/resource/coal/

[12] B. Miller and D. Tillman, Combustion Engineering Issues for Solid Fuel Systems. Amsterdam, The Netherlands: Elsevier, 2008.

[13] EIA, International Energy Outlook, Washington, DC: US Department of Energy, 2013.

[14] G. A. Richards and K. H. Casleton, "Gasification technology to produce synthesis gas", in Synthesis Gas Combustion Fundamentals and Applications, T. Lieuwen, V. Yang, and R. Yetter, Eds., New York: CRC Press Taylor and Francis Group, 2010.

[15] P. Basu, Biomass Gasification and Pyrolysis: Practical Design and Theory. United States: Elsevier; 2010.

[16] Anon, "Wood gas as engine fuel", FAO Forestry Paper, vol. 72, p. 133, 1986.

[17] M. Talmadge, M. Biddy, A. Dutta, S. Jones, and A. Meyer, "Syngas Upgrading to Hydrocarbon Fuels Technology Pathway", Denver, Colorado: U.S. Department of Energy Bioenergy Technologies Office, 2013.

[18] D. M. Alonso, J. Q. Bond, and J. A. Dumesic, "Catalytic conversion of biomass to biofuels", Green Chem., vol. 12, pp. 1493-1513, 2010. 
[19] S. Hassan, Z. A. Zainal, and M. A. Miskam, "A preliminary investigation of compressed producer gas from downdraft biomass gasifier", J. Appl. Sci., vol. 10, pp. 406-412, 2010.

[20] J. Apt, A. Newcomer, L. B. Lave, S. Douglas, and L. M. Dunn, “An Engineering-Economic Analysis of Syngas Storage", Pittsburgh: National Energy Technology Laboratory, 2008.

[21] A. Newcomer and J. Apt, "Storing syngas lowers the carbon price for profitable coal gasification", Environ. Sci. Technol., vol. 41, pp. 7974-7979, 2007.

[22] G. Sridhar, P. J. Paul, and H. S. Mukunda, "Biomass derived producer gas as a reciprocating engine fuel-an experimental analysis", Biomass Bioenerg., vol. 21, pp. 61-72, 2001.

[23] F. Y. Hagos, A. R. A. Aziz, and S. A. Sulaiman, "Trends of syngas as a fuel in internal combustion engines", Adv. Mech. Eng., vol. 2014, pp. 1-10, 2014.

[24] H. LaFontaine and G. P. Zimmerman, Construction of a Simplified Wood Gas Generator for Fueling Internal Combustion Engines in a Petroleum Emergency, Washington, DC: Federal Emergency Management Agency; 1989.

[25] E. Galloni and M. Minutillo, "Performance of a spark ignition engine fuelled with reformate gas produced on-board vehicle", Int. J. Hydrogen Energ., vol. 32, pp. 2532 2538, 2007.

[26] B. Gamiño and J. Aguillón, "Numerical simulation of syngas combustion with a multispark ignition system in a diesel engine adapted to work at the Otto Cycle", Fuel, vol. 89, pp. 581-591, 2010.

[27] N. N. Mustafi, Y. C. Miraglia, R. R. Raine, P. K. Bansal, and S. T. Elder, “Spark-ignition engine performance with 'powergas' fuel (Mixture of $\mathrm{CO} / \mathrm{H}_{2}$ ): a comparison with gasoline and natural gas", Fuel, vol. 85, pp. 1605-1612, 2006.

[28] R. G. Papagiannakis, C. D. Rakopoulos, D. T. Hountalas, and E. G. Giakoumis, “Study of the performance and exhaust emissions of a spark-ignited engine operating on syngas fuel", Int. J. Altern. Propul., vol. 1, pp. 190-215, 2007.

[29] C. D. Rakopoulos and C. N. Michos, “Development and validation of a multi-zone combustion model for performance and nitric oxide formation in syngas fueled spark ignition engine", Energy Convers. Manage., vol. 49, pp. 2924-2938, 2008.

[30] C. D. Rakopoulos, C. N. Michos, and E. G. Giakoumis, "Availability analysis of a syngas fueled spark ignition engine using a multi-zone combustion model", Energy, vol. 33, pp. 1378-1398, 2008.

[31] A. Shah, R. Srinivasan, S. D. F. To, and E. P. Columbus, "Performance and emissions of a spark-ignited engine driven generator on biomass based syngas", Bioresour. Technol., vol. 101, pp. 4656-4661, 2010.

[32] A. K. Sharma, "Experimental study on $75 \mathrm{~kW}_{\text {th }}$ downdraft (biomass) gasifier system", Renew. Energ., vol. 34, pp. 1726-1733, 2009. 
[33] J. A. Smith and G. J. J. Bartley, "Stoichiometric operation of a gas engine utilizing synthesis gas and EGR for $\mathrm{NO}_{x}$ control", J. Eng. Gas Turbines Power, vol. 122, pp. 617$623,2000$.

[34] G. Sridhar, "Experimental and modeling aspects of producer gas engine", in Sustainable Energy Technologies (ICSET 2008) International Conference, Singapore, 2008, pp. 995-1000.

[35] A. K. Rajvanshi, "Biomass gasification", in Alternative Energy in Agriculture. vol. 2, D. Y. Goswami, Ed., New York: CRC Press, 1986, pp. 83-102.

[36] S. Dasappa, P. J. Paul, H. S. Mukunda, N. K. S. Rajan, G. Sridhar, and H. V. Sridhar, "Biomass gasification technology - a route to meet energy needs", Curr. Sci. India, vol. 87, pp. 908-916, 2004.

[37] J. Ahrenfeldt, E. V. Foged, R. Strand, and U. B. Henriksen, Development and Test of a New Concept for Biomass Producer Gas Engines, Risø National Laboratory for Sustainable Energy, Technical University of Denmark, Roskilde ISBN 978-87-550-3811-0, 2010.

[38] J. Ahrenfeldt, T. K. Jensen, U. Henriksen, J. Schramm, and B. Gøbel, “CO emissions from gas engines operating on biomass producer gas", presented at the World Conference and Technology Exhibition on Biomass for Energy and Industry Florence, Italy, 2004.

[39] V. Belgiorno, G. D. Feo, C. D. Rocca, and R. M. A. Napoli, "Energy from gasification of solid wastes", Waste Manage. (Oxford), vol. 23, pp. 1-15, 2003.

[40] V. B. Kovács and A. Meggyes, "Investigation of utilization of low heating value gaseous fuels in gas engine", in 4th European Combustion Meeting, Vienna University of Technology, Vienna, Austria, 2009.

[41] F. V. Tinaut, A. Melgar, A. Horrillo, and A. D. de la Rosa, "Method for predicting the performance of an internal combustion engine fuelled by producer gas and other low heating value gases", Fuel Process Technol., vol. 87, pp. 135-142, 2006.

[42] S.S.Vinay, S.D.Ravi, G. PremaKumar, and N.K.S. Rajan, “Numerical and experimental modeling of producer gas carburettor", in Advances in Mechanical Engineering, S.V. National Institute of Technology, Surat, Gujarat, India, 2008.

[43] G. Przybyla, L. Ziolkowski, and A. Szlek, "Performance of SI engine fuelled with LCV gas", presented at the Second International Workshop on Biomass Gasification Technologies (BIOGASTECH) Gebze, Turkey, 2008.

[44] Y. Ando, K. Yoshikawa, M. Beck, and H. Endo, "Research and development of a lowBTU gas-driven engine for waste gasification and power generation", Energy, vol. 30, pp. 2206-2218, 2005.

[45] V. Sadykov, V. Sobyanin, V. Kirillov, V. Kuzmin, N. Kuzin, Z. Vostrikov, et al., “Syngas as a fuel for IC and diesel engines: efficiency and harmful emissions cut-off", presented 
at the International Hydrogen Energy Congress and Exhibition (IHEC 2005), Istanbul, Turkey, 2005.

[46] E. Toulson, H. Watson, and W. Attard, "The lean limit and emissions of a gasoline HAJI system that employs syngas in place of hydrogen as the prechamber fuel", in International Federation of Automotive Engineering Societies (FISITA) World Automotive Congress, Munich, Germany, 2008.

[47] A. S. Bika, Synthesis Gas Use in Internal Combustion Engines, PhD, Faculty of Graduate School, University of Minnesota, Minnesota, 2010.

[48] C. T. Spaeth, Performance Characteristics of a Diesel Fuel Piloted Syngas Compression Ignition Engine, Master of Applied Science, Department of Mechanical and Materials Engineering, Queen's University, 2012.

[49] F. Konigsson, Advancing the Limits of Dual Fuel Combustion, Licentiate, Department of Machine Design, Stockholm, Sweden: Royal Institute of Technology (KTH), 2012.

[50] U. Azimov, E. Tomita, N. Kawahara, and Y. Harada, “Effect of syngas composition on combustion and exhaust emission characteristics in a pilot-ignited dual-fuel engine operated in PREMIER combustion mode", Int. J. Hydrogen Energ., vol. 36, pp. 1198511996, 2011.

[51] B. B. Sahoo, N. Sahoo, and U. K. Saha, "Effect of $\mathrm{H}_{2}$ :CO ratio in syngas on the performance of a dual fuel diesel engine operation", Appl. Therm. Eng., vol. 49, pp. 139-146, 2012.

[52] B. B. Sahoo, U. K. Saha, and N. Sahoo, "Theoretical performance limits of a syngasdiesel fueled compression ignition engine from second law analysis", Energy, vol. 36, pp. 760-769, 2011.

[53] A. M. L. M. Wagemakers and C. A. J. Leermakers, "Review on the effects of dual-fuel operation, using diesel and gaseous fuels, on emissions and performance", SAE Paper 2012-01-0869, 2012, doi:10.4271/2012-01-0869.

[54] S. Hassan, Z. A. Zainal, and M. A. Miskam, "Performance and emission characteristics of supercharged biomass producer gas-diesel dual fuel engine", J. Appl. Sci., vol. 11, pp. 1606-1611, 2011.

[55] F. Y. Hagos, A. R. A. Aziz, and S. A. Sulaiman, "Syngas $\left(\mathrm{H}_{2} / \mathrm{CO}\right)$ in a spark-ignition direct-injection engine. Part 1: Combustion, performance and emissions comparison with CNG", Int. J. Hydrogen Energ., vol. 39, pp. 17884-17895, 2014.

[56] F. Y. Hagos and A. R. A. Aziz, "Mass fraction burn investigation of lean burn low BTU gasification gas in direct-injection spark-ignition engine", SAE Technical Paper 2014-01-1336, 2014, doi:10.4271/2014-01-1336. 
[57] F. Y. Hagos, A. R. A. Aziz, and S. A. Sulaiman, "Combustion characteristics of directinjection spark-ignition engine fuelled with producer gas", Energy Educ. Sci. Technol. Part A: Energy Sci. Res., vol. 31, pp. 1683-1698, 2013.

[58] F. Y. Hagos, A. R. A. Aziz, and S. A. Sulaiman, "Effect of air-fuel ratio on the combustion characteristics of syngas $\left(\mathrm{H}_{2}: \mathrm{CO}\right)$ in direct-injection sparkignition engine", Energy Procedia, vol. 61, pp. 2567-2571, 2014.

[59] F. Y. Hagos, A. R. A. Aziz, and S. A. Sulaiman, "Early flame development image comparison of low calorific value syngas and CNG in DI SI gas engine", in IOP Conference Series: Earth and Environmental Science, Putrajaya, Malaysia, 2013, p. 012070.

[60] F. Y. Hagos, A. A. A. Rashid, and S. A. Sulaiman, "Study of syngas combustion parameters effect on internal combustion engines", Asian J. Sci. Res., vol. 6, pp. 187-196, 2013.

[61] M. Morri, L. Waldheim, A. Faaij, and K. Stahl. “Status of large-scale biomass gasification and prospects", in Handbook Biomass Gasification, H. Knoef and J. Ahrenfeldt, Eds., Enschede, The Netherlands: Biomass Technology Group (BTG), 2005.

[62] J. Holmala J. Isaksson, and Metso, "Metso-supplied world's largest biomass gasification plant inaugurated in Finland", Helsinki, Finland: Metso Corporation, 2013.

[63] C. Erdalen, GoBiGas, "Göteborg Energi's biogas plant GoBiGas is now fully operational”, Göteborg, Sweden: Göteborg Energi AB, 2014.

[64] P. McKendry, "Energy production from biomass (part 1): overview of biomass", Bioresource Technol., vol. 83, pp. 37-46, 2002.

[65] R. Konda, S. Sulaiman, and B. Ariwahjoedi, "Syngas production from gasification of oil palm fronds with an updraft gasifier", J. Appl. Sci., vol. 12, p. 2555, 2012.

[66] S. M. Atnaw, S. A. Sulaiman, and S. Yusup, "Syngas production from downdraft gasification of oil palm fronds", Energy, vol. 61, pp. 491-501, 2013.

[67] S. M. Atnaw, S. A. Sulaiman, and S. Yusup, "Influence of fuel moisture content and reactor temperature on the calorific value of syngas resulted from gasification of oil palm fronds", Sci. World J., vol. 2014, pp. 1-9, 2014.

[68] H. Hofbauer and H. Knoef, "Success stories on biomass gasification", in Handbook Biomass Gasification, H. Knoef and J. Ahrenfeldt, Eds., Enschede, The Netherlands: Biomass Technology Group (BTG), 2005.

[69] M. Paisley and R. Overend, "Verification of the performance of future energy resources' SilvaGas (R) biomass gasifier-operating experience in the vermont gasifier", in Pittsburgh Coal Conference, Pittsburgh, PA, 2002.

[70] A. Kaupp and J. Goss, State-of-the-Art Report for Small Scale (to $50 \mathrm{kw}$ ) Gas Producer-engine Systems, Department of Agricultural Engineering: California University, Davis (USA); 1981. 
[71] K. Von Mitzlaff, "Engines for biogas", German Appropriate Technology Exchange (GATE), Deutsche Gesellschaft fÃ¹/4r Technische Zusammenarbeit (GTZ), 1988.

[72] D. Granatstein, Case Study on Lahden Lämpövoima Gasification Project, Kymijärvi Power Station, Lahti, Finland, Varennes, QC, Canada: Natural Resources Canada/CANMET Energy Technology Centre (CETC) 2002.

[73] K. Von Mitzlaff, "Engines for biogas", German Appropriate Technology Exchange (GATE), Deutsche Gesellschaft für Technische Zusammenarbeit (GTZ), 1988.

[74] C. S. Weaver and S. H. Turner, "Dual fuel natural gas/diesel engines: technology, performance, and emissions", SAE Technical Paper 0148-7191, 1994, doi:10.4271/940548.

[75] G. Karim and M. Khan, "Examination of effective rates of combustion heat release in a dual-fuel engine", J. Mech. Eng. Sci., vol. 10, pp. 13-23, 1968.

[76] G. A. Karim, "A review of combustion processes in the dual fuel engine-the gas diesel engine", Prog. Energy Combust. Sci., vol. 6, pp. 277-285, 1980.

[77] C. Rakopoulos and D. Kyritsis, "Comparative second-law analysis of internal combustion engine operation for methane, methanol, and dodecane fuels", Energy, vol. 26, pp. 705-722, 2001.

[78] C. Rakopoulos and D. Kyritsis, "Hydrogen enrichment effects on the second law analysis of natural and landfill gas combustion in engine cylinders", Int. J. Hydrogen Energy, vol. 31, pp. 1384-1393, 2006.

[79] C. Rakopoulos and C. Michos, "Generation of combustion irreversibilities in a spark ignition engine under biogas - hydrogen mixtures fueling", Int. J. Hydrogen Energ., vol. 34, pp. 4422-4437, 2009.

[80] A. S. Ramadhas, S. Jayaraj, and C. Muraleedharan, "Dual fuel mode operation in diesel engines using renewable fuels: rubber seed oil and coir-pith producer gas", Renewable Energ., vol. 33, pp. 2077-2083, 2008.

[81] B. K. Mahgoub, S. Sulaiman, and Z. Abdul Karim, "Performance study of imitated syngas in a dual-fuel compression ignition diesel engine", Int. J. Automotive Mech. Eng., vol. 11, pp. 2282-2293, 2015.

[82] M. M. Roy, E. Tomita, N. Kawahara, Y. Harada, and A. Sakane, "Performance and emission comparison of a supercharged dual-fuel engine fueled by producer gases with varying hydrogen content", Int. J. Hydrogen Energ., vol. 34, pp. 7811-7822, 2009.

[83] E. Tomita, N. Fukatani, N. Kawahara, K. Maruyama, and T. Komoda, “Combustion characteristics and performance of supercharged pyrolysis gas engine with micro-pilot ignition", in CIMAC Congress, Vienna, Austria, 2007.

[84] R. Papagiannakis and D. Hountalas, “Combustion and exhaust emission characteristics of a dual fuel compression ignition engine operated with pilot diesel fuel and natural gas", Energy Convers. Manage., vol. 45, pp. 2971-2987, 2004. 
[85] H. E. Saleh, "Effect of variation in LPG composition on emissions and performance in a dual fuel diesel engine", Fuel, vol. 87, pp. 3031-3039, 2008.

[86] N. Saravanan and G. Nagarajan, "Experimental investigation in optimizing the hydrogen fuel on a hydrogen diesel dual-fuel engine", Energy Fuels, vol. 23, pp. 26462657, 2009.

[87] N. Saravanan and G. Nagarajan, "Experimental investigation on performance and emission characteristics of dual fuel DI diesel engine with hydrogen fuel", SAE Technical Paper, 2009, doi:10.4271/2009-26-0032.

[88] N. Saravanan, G. Nagarajan, K. Kalaiselvan, and C. Dhanasekaran, “An experimental investigation on hydrogen as a dual fuel for diesel engine system with exhaust gas recirculation technique", Renewable Energy, vol. 33, pp. 422-427, 2008.

[89] U. Azimov, E. Tomita, N. Kawahara, and S. S. Dol, “Combustion characteristics of syngas and natural gas in micro-pilot ignited dual-fuel engine", World Academy of Science, Engineering and Technology, vol. 72, pp. 1614-1621, 2012.

[90] A. S. Bika, L. M. Franklin, and D. B. Kittelson, "Emissions effects of hydrogen as a supplemental fuel with diesel and biodiesel", SAE Int. J. Fuels Lubric., vol. 1, pp. 283292, 2008.

[91] T. Lieuwen, V. Yang, and R. Yetter, Synthesis Gas Combustion: Fundamentals and Applications. New York: CRC Press, 2009.

[92] R. J. Nichols, "Challenges of change in the auto industry: why alternative fuels?", in The 15 th Annual Fall Technical Conference of the ASME Internal Combustion Engine Division, Morgantown, WV, USA, 09/26-29/93, 1993, pp. 3-10.

[93] C. S. Weaver, "Natural gas vehicles-a review of the state of the art", SAE Technical Paper, 892133 1989, doi:10.4271/892133.

[94] A. Bilcan, O. Le Corre, M. Tazerout, A. Ramesh, and S. Ganesan, “Characterization of the LPG-diesel dual fuel combustion", SAE Technical Paper, 2001-28-0036 2001, doi: 10.4271/2001-28-0036.

[95] D. Gera, M. P. Mathur, M. C. Freeman, and A. Robinson, "Effect of large aspect ratio of biomass particles on carbon burnout in a utility boiler", Energy Fuels, vol. 16, pp. 15231532, 2002.

[96] B. K. M. Mahgoub, S. A. Sulaiman, and Z. A. B. A. Karim, “Emission of a compression ignition engine fuelled by diesel and imitated syngas", in AIP Conference Proceedings, 2012, p. 964.

[97] G. Sridhar, S. Dasappa, H. V. Sridhar, P. J. Paul, and N. K. S. Rajan, “Gaseous emissions using producer gas as fuel in reciprocating engines", SAE Technical Paper 10.4271/2005-01-1732, 2005, doi:10.4271/2005-01-1732. 
[98] H. M. Cho and B.-Q. He, "Spark ignition natural gas engines-a review", Energy Convers. Manage., vol. 48, pp. 608-618, 2007.

[99] E. Monteiro, M. Bellenoue, J. Sottton, and A. Rouboa, "Syngas application to spark ignition engine working simulations by use of rapid compression machine", in Internal Combustion Engines, K. Lejda and P. Wos, Eds., Rijeka, Croatia: InTech, 2012, pp. 51-74.

[100] J. Ahrenfeldt, Characterization of Biomass Producer Gas as Fuel for Stationary Gas Engines in Combined Heat and Power Production, Degree for Doctor of Philosophy, Technical University of Denmark: Department of Mechanical Engineering; 2007.

[101] F. Y. Hagos, A. R. A. Aziz, and S. A. Sulaiman, "Effect of injection timing on combustion, performance and emissions of lean-burn syngas $(\mathrm{H} 2 / \mathrm{CO})$ in spark-ignition directinjection engine", Int. J. Engine Res., 2015, doi: 10.1177/1468087415623910.

[102] NFPA, The Vehicular Gaseous Fuel Systems Code, Quincy, Massachusetts: National Fire Protection Association, 2010.

[103] F. Y. Hagos, A. R. A. Aziz, and S. A. Sulaiman, “Methane enrichment of syngas $\left(\mathrm{H}_{2} / \mathrm{CO}\right)$ in a spark-ignition direct-injection engine: combustion, performance and emissions comparison with syngas and compressed natural gas", Energy, vol. 90, pp. 2006-2015, 2015.

[104] T. C. Williams and C. R. Shaddix, "Contamination of carbon monoxide with metal carbonyl: implications for combustion research", Combust. Sci. Technol., vol. 179, pp. 1225-1230, 2007.

[105] C. Wyse, J. Vininski, and T. Watanabe, “Cylinder, purifier technologies for controlling contamination in CO", Solid State Technol., vol. 45, pp. 125-129, 2002.

[106] F. Hagos, A. Aziz, and S. Sulaiman, "Investigation of deposit formation in directinjection spark-ignition engine powered on syngas", Int. J. Automotive Technol., vol. 16, pp. 479-485, 2015 
